University of Nebraska - Lincoln

DigitalCommons@University of Nebraska - Lincoln

1990

\title{
Influence of Mineral-Bound Humic Substances on the Sorption of Hydrophobic Organic Compounds
}

\author{
Ellyn M. Murphy \\ Pacific Northwest National Laboratory \\ John M. Zachara \\ Pacific Northwest National Laboratory, john.zachara@pnl.gov \\ Steven C. Smith \\ Pacific Northwest National Laboratory
}

Follow this and additional works at: https://digitalcommons.unl.edu/usdoepub

Part of the Bioresource and Agricultural Engineering Commons

Murphy, Ellyn M.; Zachara, John M.; and Smith, Steven C., "Influence of Mineral-Bound Humic Substances on the Sorption of Hydrophobic Organic Compounds" (1990). US Department of Energy Publications. 207. https://digitalcommons.unl.edu/usdoepub/207

This Article is brought to you for free and open access by the U.S. Department of Energy at DigitalCommons@University of Nebraska - Lincoln. It has been accepted for inclusion in US Department of Energy Publications by an authorized administrator of DigitalCommons@University of Nebraska - Lincoln. 


\title{
Influence of Mineral-Bound Humic Substances on the Sorption of Hydrophobic Organic Compounds
}

\author{
Ellyn M. Murphy," John M. Zachara, and Steven C. Smith
}

This article is a U.S. government work, and is not subject to copyright in the United States.

Geosciences Department, Pacific Northwest Laboratory, Richland, Washington 99352

\begin{abstract}
The sorption of three hydrophobic organic compounds (HOC) was investigated on hematite and kaolinite that had been coated with natural humic substances over a mass percent carbon range of $0.01-0.5 \%$. Increasing quantities of sorbed humic substances increased the sorption of HOC. Anthracene, the most hydrophobic HOC, showed the greatest sorption enhancement, while the most aromatic coating, peat humic acid, was the strongest sorbent. Depending on the type of humic acid coating and the mineral substrate, the experimental $K_{o c}$ values were either higher or lower than those predicted by the $K_{\text {ow. }}$. The sorptivity of a given humic acid for HOC was not the same on kaolinite and hematite, suggesting that the orientation and structure of the humic substance on the mineral may affect the surface area of the organic phase and the accessibility of hydrophobic domains that control HOC sorptivity. Sorption isotherms for HOC on the humic-coated mineral substrates were nonlinear, implying that the sorption phenomenon was adsorption onto rather than partitioning into the surface organic phase.
\end{abstract}

\section{Introduction}

The sorption of hydrophobic organic compounds (HOC) to organic matter in soil, sediment, and aquifer material and the binding of HOC to dissolved and colloidal humic substances are dominant processes controlling the aqueous concentrations and transport of $\mathrm{HOC}$ in the environment. Carbon-normalized binding constants $\left(K_{o c}\right)$ for different $\mathrm{HOC}$ on soils and natural humic substances correlate well with the solute's octanol-water partition coefficient $\left(K_{\text {ow }}\right)$ (1-3). Empirical equations based on such correlations with $K_{\text {ow }}$ are commonly used to estimate the $K_{\text {oc }}$ of natural sorbents for environmental fate and transport calculations.

The structural and bulk chemical properties of organic matter in soils and subsoils vary between different climatic and geochemical environments (4), and these variations influence HOC sorption (5-7). For different soils, the $K_{\mathrm{oc}}$ of a single $\mathrm{HOC}$ may range over an order of magnitude, and such variations may be attributed to compositional differences in the organic matter, such as polarity and aromaticity $(1,6,8)$. Similarly, investigations of HOC binding to aqueous organic phases have shown that the intensity of sorption is dependent on the origin (9), molecular weight $(10,11)$, and polarity and molecular configuration $(10,12,13)$ of the humic substance. Specifically, less polar humic substances with low $0 / C$ ratios show greater binding affinity for HOC.

Experimental observations of $K_{\mathrm{oc}}$ (calculated by assuming no mineral contribution to sorption) for less hydrophobic compounds on low-carbon materials have sometimes deviated significantly from predictions of $K_{\mathrm{oc}}$ based on empirical $K_{\text {oc }}-K_{\text {ow }}$ relationships. Such observations strongly suggest that mineral surfaces contribute to HOC sorption $(1,14-18)$. Recognizing this effect, McCarty et al. (19) and Karickhoff (1) proposed a group contribution model for sorption, in which both partitioning into organic matter and adsorption onto mineral surfaces control the overall HOC sorption. Curtis et al. (18) performed sensitivity calculations on these effects and showed that, at low $f_{\circ \mathrm{c}}(0.0002)$, mineral effects become important for HOC with $\log K_{\text {ow }}<4$. Thus, the dominance of one sorptive phase over the other is controlled by $K_{\text {ow }}, K_{\text {oc }}, f_{\text {oc }}$, and surface area of the mineral sorbent (18).

The $K_{\mathrm{oc}}$ may also be influenced by the nature of the mineral-organic association $(6,20)$. This would be significant to groundwater materials in which the physiochemical nature of the organic phase may be different from that of near-surface soils and sediments, in which the organic matter has arisen from direct biochemical transformation of biotic remains. In aquifer sediments, the organic matter may be (1) lithified or fossiliferous plant remains, such as lignite or kerogen, or (2) particle-associated humic substances that have been transported as dissolved organic carbon (DOC) from the overlying soil and vadose zone. The particle-associated humic substances may in fact form mineral coatings, given that natural dissolved/colloidal organic material binds to a variety of mineral surfaces that are common in aquifers (21-28). These organic coatings may render hydrophilic surfaces hydrophobic and more capable or sorbing organic compounds. Organic coatings have not been identified on aquifer sediments specifically, but they are expected to occur to varying degrees, depending on aquifer mineralogy, water chemistry, and the composition and nature of the DOC.

In view of the inherent complexity of natural organicmineral systems, the role of humic coatings and mineral surfaces in the sorption of HOC by low-carbon aquifer materials might most easily be defined by an investigation using well-characterized mineral substrates and reference organic substances. Therefore, the objectives of the current study were to (1) investigate the sorption of reference humic substances on typical aquifer sediments, (2) determine the dependence of HOC sorptivity on the fractional surface coverage of mineral surfaces with humic substances, (3) establish whether HOC sorptivity was influenced by the aromaticity/aliphilicity of the humic coating, and (4) identify whether different mineral surfaces imparted a different structure to the adsorbed organic substances that in turn affected HOC sorption.

\section{Experimental Procedures}

Sorbents. Kaolinite, hematite, and a clay fraction (CP-clay) from a subsurface soil horizon that contained both kaolinite and hematite were used in these experiments. Selected properties of these sorbents are listed in Table I.

The well-crystallized kaolinite (KGa-1), Clay Minerals Society source clay) was prepared according to the method of Johnston et al. (29) and Zachara et al. (30). This procedure removes oxide and hydroxide coatings from the kaolinite surface after the desired clay-size fraction $(0.2-2.0$ $\mu \mathrm{m}$ ) has been isolated by sedimentation and centrifugation. The kaolinite was stored in $0.1 \mathrm{M} \mathrm{NaClO}$ at $4^{\circ} \mathrm{C}$. Immediately before use, the clay was treated with $\mathrm{H}_{2} \mathrm{O}_{2}$ to remove oxidizable organic material (37).

Hematite was synthesized by preparing a $0.17 \mathrm{M} \mathrm{FeCl}_{3}$ solution with boiled and $\mathrm{N}_{2}$-sparged deionized water. The 
Table I. Properties of Mineral Sorbents

\begin{tabular}{llll} 
& kaolinite & hematite & \multicolumn{1}{c}{ CP-clay } \\
surface area, ${ }^{a} \mathrm{~m}^{2} / \mathrm{g}$ & 15.6 & 5.41 & 68.2 \\
OH sites, ${ }^{b} \mathrm{~mol} / \mathrm{g}$ & $1.56 \times 10^{-5}$ & $8.98 \times 10^{-5}$ & $2.26 \times 10^{-5}$ \\
$\mathrm{HOC}$ expt concn, ${ }^{c} \mathrm{~g} / \mathrm{L}$ & 100 & 74 & 24 \\
$\mathrm{HOC}$ expt surface area, & 1600 & 400 & 1600 \\
$\mathrm{~m}^{2} / \mathrm{L}$ & & & \\
$\mathrm{pH}_{\mathrm{zpc}}$ & $7.3^{d}$ & $8.5^{e}$ & $5.3^{f}$
\end{tabular}

a Surface area was measured by triple-point $\mathrm{N}_{2}$ (g) adsorption and calculated by using BET equation. ${ }^{b}$ Kaolinite $(30,31)$; hematite $(32,33)$; CP-clay (34). 'Sorbent concentration used in the HOC experiments. ${ }^{d}$ Apparent $\mathrm{pH}_{\mathrm{zpc}}$ of the kaolinite edge $(35,36)$. References 32 and 33 . $f$ The $\mathrm{pH}$ reported for CP-clay is the equilibrium $\mathrm{pH}$ value, not a $\mathrm{pH}_{2 \mathrm{pc}}$.

solution was adjusted to $\mathrm{pH} 12$ with $\mathrm{CO}_{2}$-free $2 \mathrm{M} \mathrm{NaOH}$, inducing precipitation of iron oxide, and the suspension was stored overnight at $60^{\circ} \mathrm{C}$. The precipitate was dialyzed aganist deionized water until the exterior solution maintained a relatively constant conductivity, approximately 14 days. The resulting iron oxide (crystalline goethite) was freeze-dried and converted to hematite by heating at $700^{\circ} \mathrm{C}$ for $72 \mathrm{~h}$.

The CP-clay fraction was isolated from a North Carolina subsurface soil (Bc horizon, Cecil/Pacolet series, Typic Hapludult). The clay fraction $(<2.0 \mu \mathrm{m})$ was separated from the soil by sedimentation after sonification for dispersion. The clay fraction was repeatedly washed with 0.1 M $\mathrm{NaClO}_{4}$, dialyzed against deionized $\mathrm{H}_{2} \mathrm{O}$ for several days, and stored as suspensions with chloroform added to suppress microbiologic activity. On a mass percentage basis, the clay fraction was dominated by kaolinite $(\sim$ $80 \%$ ), with minor amounts of hematite $(5 \%)$, goethite $(5 \%)$, and vermiculite. Before use in the HOC experiments, the clay was treated with $\mathrm{H}_{2} \mathrm{O}_{2}$. The $K_{o c}$ for the sorption of dibenzothiophene on natural, untreated, CP. clay was also determined. The clay fraction had an organic carbon content of $0.04 \%$.

Organic Compounds. Well-characterized humic substances were obtained from the International Humic Substances Society (IHSS). "Humic substances" is a generic term referring to humic acids, fulvic acids, and the relatively insoluble humin fraction of natural organic matter. The IHSS peat humic and fulvic acids were isolated from Pohokee peat (Ocachobee, FL), and the IHSS Suwannee River humic and fulvic acids were isolated from the Suwannee River, which drains the Okefenokee Swamp in southern Georgia. The distribution of carbon functional groups and the elemental analyses of the humic and fulvic acids are shown in Table II.

Uniformly ${ }^{14} \mathrm{C}$ ring labeled compounds were customsynthesized by Sigma and used to quantify sorption. The integrity of the tracer compounds was verified by HPLC. The radiochemical purity of carbazole was determined to be greater than $99 \%$ with a specific activity of $9.2 \mathrm{Ci} / \mathrm{mol}$. Dibenzothiophene had a purity greater than $98 \%$ with a specific activity of $12.6 \mathrm{Ci} / \mathrm{mol}$, and anthracene had a purity greater than $99 \%$ with a specific activity of 20 $\mathrm{Ci} / \mathrm{mol}$.

Sorption of Humic Substances. All of the sorption experiments and results depended on accurate direct measurements of DOC. Therefore, precautions were taken to ensure that glassware was clean and that all electrolyte and reagent solutions were at or below our analytical DOC detection limit $(0.4 \mathrm{mg} / \mathrm{L})$. Selected glassware (reaction flask and Corex tubes described below) was cleaned with hot, concentrated $\mathrm{H}_{2} \mathrm{SO}_{4}$ and $\mathrm{HNO}_{3}$ (ratio of 85:15), followed by several rinses in MilliQ water. All other glassware was washed, soaked in $0.25 \mathrm{M} \mathrm{HNO}_{3}$, and rinsed with MilliQ water.

The sorption of humic substances was measured on kaolinite and hematite over a $\mathrm{pH}$ range of $4-7.5$ in a $250-\mathrm{mL}$ jacketed glass flask maintained at $25^{\circ} \mathrm{C}$ under nitrogen atmosphere. A surface area of $55 \mathrm{~m}^{2} / \mathrm{L}$ was used in the kaolinite experiments; a surface area of $25 \mathrm{~m}^{2} / \mathrm{L}$ was used for hematite. The experiment was initiated by raising the $\mathrm{pH}$ of the sorbent suspensions (in $0.1 \mathrm{M} \mathrm{NaClO}_{4}$ ) to $\mathrm{pH} 8.0$ with a titrator $/ \mathrm{pH}$ stat and allowing the suspension to equilibrate for $12 \mathrm{~h}$. The sorbent suspension was then spiked to yield a $\sim 10 \mathrm{mg}$ of $\mathrm{C} / \mathrm{L}$ initial DOC concentration of the humic substance. This suspension was allowed to equilibrate at $\mathrm{pH} 8.0$ for only $30 \mathrm{~min}$ to prevent hydrolysis of the humic substances at high $\mathrm{pH}$. Aliquots $(2 \times 10 \mathrm{~mL})$ of the suspension were removed to 25-mL Corex tubes. The $\mathrm{pH}$ was sequentially lowered by $0.5 \mathrm{pH}$ unit and allowed to equilibrate for $\sim 1 \mathrm{~h}$, and then samples were removed. This procedure was followed until a $\mathrm{pH}$ of 4.0 was attained. The Corex tubes were placed on a shaker for $12 \mathrm{~h}$ at $25^{\circ} \mathrm{C}$ and then centrifuged, and the supernatant was analyzed for DOC and $\mathrm{pH}$. All DOC analyses were performed on a Dorhman carbon analyzer. Mineral blanks allowed for the assessment of the amount of background DOC released by the sorbents. Pretreating the sorbents (i.e., treating the kaolinite with $\mathrm{H}_{2} \mathrm{O}_{2}$ and the hematite at $700^{\circ} \mathrm{C}$ ) was found to reduce background DOC to minimal values.

HOC Sorption Over a Range in $\boldsymbol{f}_{\text {oc }}$. The kaolinite, hematite, and CP-clay were coated with either peat humic acid or Suwannee humic acid by equilibrating the sorbents with varying amounts of dissolved humic substance $(0-\sim$ $90 \mathrm{mg} / \mathrm{L}$ ) in $0.1 \mathrm{M} \mathrm{NaClO}_{4}$ at $\mathrm{pH} 4.5$ for $20 \mathrm{~h}$. A timecourse study showed that equilibrium sorption of humic acid with hematite occurs within the first hour, and with kaolinite it occurs within 8-10 h. The $\mathrm{pH}$ was maintained at 4.5 with a titrator $/ \mathrm{pH}$ stat while the mineral sorbents were being loaded with the humic substances. The suspension was then centrifuged ( $3000 \mathrm{~g}$, for $20 \mathrm{~min}$ ), and the humic acid in the supernatant was analyzed by measurement of the DOC. The coated sorbent was washed once with DOC-free $0.1 \mathrm{M} \mathrm{NaClO}_{4}$ and centrifuged, and the $\mathrm{DOC}$ of the supernatant was analyzed. The humic-coated sorbent suspension was then concentrated $\sim 4$ times by decanting the supernatant and resuspending the sorbent

Table II. Chemical Properties of IHSS Reference Humic Substances ${ }^{a}$

$\begin{array}{lccc} & \text { aromatic C } & \text { aliphatic C } & \text { carboxyl C } \\ \text { IHSS ref material } & (110-165) & (0-90) & (165-190)\end{array}$

peat humic acid
Suwannee humic acid
peat fulvic acid

Suwannee fulvic acid

47
37
34
24

$\begin{array}{ll}24 & 20 \\ 28 & 19 \\ 29 & 28 \\ 44 & 44\end{array}$

$\begin{array}{cccccc}\mathrm{C} & \mathrm{H} & \mathrm{O} & \mathrm{N} & \text { ash } & \mathrm{O} / \mathrm{C} \\ 56.82 & 4.06 & 34.91 & 3.74 & 1.92 & 0.46 \\ 54.34 & 4.08 & 39.43 & 1.08 & 3.38 & 0.54 \\ 51.54 & 3.51 & 42.58 & 2.31 & 1.59 & 0.62 \\ 53.50 & 4.24 & 41.29 & 0.69 & 0.82 & 0.58\end{array}$

a The distribution in percent of carbon functional groups was determined by liquid-state ${ }^{13} \mathrm{C}$ NMR (ppm range shown in parentheses) (40), Elemental analyses were performed by Huffman Laboratories and oxygen was measured directly (Golden, Colorado; R. L. Malcolm, personal communication). 
in a smaller volume of DOC-free $0.1 \mathrm{M} \mathrm{NaClO}_{4}$. Aliquots of the sorbent suspension were transferred to tared, 8.5$\mathrm{mL}$, glass centrifuge tubes to measure HOC sorption (described below). The $f_{o c}$ contributed by the sorbed humic substances ranged from $\sim 0.01$ to $0.5 \%$ for hematite and kaolinite, and from $\sim 0.06$ to $1.0 \%$ for the CP-clay. In addition, each experiment was repeated with a mineral blank (i.e., the sorbent with no humic coating) to assess HOC sorption to the mineral surface and a "no-HOC" blank (containing the coated mineral only) to determine the extent of desorption of the bound humic substances.

Radiolabeled carbazole, dibenzothiophene, or anthracene solutions were added to the concentrated sorbent suspensions to reach a final working concentration of $25 \%$ of the compound's water solubility. Sorption of HOC on the humic-mineral sorbents was not great, and large sorbent concentrations were required to achieve a significant percentage change in the sorbate concentration $(>25 \%)$ during the sorption measurement. The final surface area concentrations of kaolinite, CP-clay, and hematite were 1600,1600 , and $400 \mathrm{~m}^{2} / \mathrm{L}$, respectively. Headspace was $0.5 \mathrm{~cm}^{3}$ in the $8.5-\mathrm{cm}^{3}$ centrifuge tube to minimize volatilization of the compounds, especially anthracene, which has a high Henry's law constant. The tube caps were lined with aluminum foil because preliminary studies indicated that the compounds sorbed to the Teflon-lined cap. Light was excluded from the anthracene experiments to prevent photodegradation. The suspensions were equilibrated with slow end-over-end mixing for $20 \mathrm{~h}$ at $25^{\circ} \mathrm{C}$. The suspensions were then centrifuged at $3000 \mathrm{~g}$, and $1-\mathrm{mL}$ aliquots of the supernatant were transferred to tared scintillation vials containing $12 \mathrm{~mL}$ of scintillation cocktail. The $\mathrm{pH}$ of the supernatant was determined, and the "no-HOC" blank was analyzed for DOC. Desorption of the humic coating was not measurable over the course of these experiments.

The fraction of HOC adsorbed in these batch experiments was calculated by difference based on the ${ }^{14} \mathrm{C}$ counts remaining in solution. To test the experimental procedures, $\mathrm{HOC}$ were desorbed from hematite coated with peat humic acid by resuspending the pellet in acetone. The tubes were placed in a shaker for 7 days and centrifuged, and 1-mL aliquots were counted as above. An average of $92 \%$ of the calculated sorbed HOC was recovered by this method.

HOC Sorption Isotherms at Constant $\boldsymbol{f}_{\text {oc }}$. Isotherms for carbazole, dibenzothiophene, and anthracene were determined for hematite $\left(200 \mathrm{~m}^{2} / \mathrm{L}\right)$ and kaolinite $(800$ $\left.\mathrm{m}^{2} / \mathrm{L}\right)$ coated with low $\left(f_{x}=0.02 \%\right)$ and high $\left(f_{x c}=0.25 \%\right)$ concentrations of peat humic acid. The preparation of the coated hematite was identical with the procedure outlined above. Four-point isotherms were determined by using ${ }^{14} \mathrm{C}$-labeled carbazole, dibenzothiophene, and anthracene solutions ranging from 0.09 to $1.24 \mathrm{mg} / \mathrm{L}$, from 0.22 to 0.86 $\mathrm{mg} / \mathrm{L}$, and from 0.01 to $0.06 \mathrm{mg} / \mathrm{L}$, respectively. Triplicate samples were run at each HOC concentration. As in the batch $\mathrm{HOC}$ experiments, $0.1 \mathrm{M} \mathrm{NaClO}_{4}$ was used as the electrolyte. The HOC was allowed to equilibrate with the coated hematite with slow end-over-end mixing for $20 \mathrm{~h}$. The suspensions were centrifuged at $3000 \mathrm{~g}$ and the supernatant was sampled for ${ }^{14} \mathrm{C}$ activity. The supernatant was carefully decanted and the HOC was desorbed from the sorbent with acetone. The bound HOC was determined directly by ${ }^{14} \mathrm{C}$ activity.

Humic Acid Fractionation Study. Suwannee humic acid was sequentially reacted with hematite to determine whether the humic acid fractionates as it adsorbs to the hematite surface and if such fractionation creates coatings

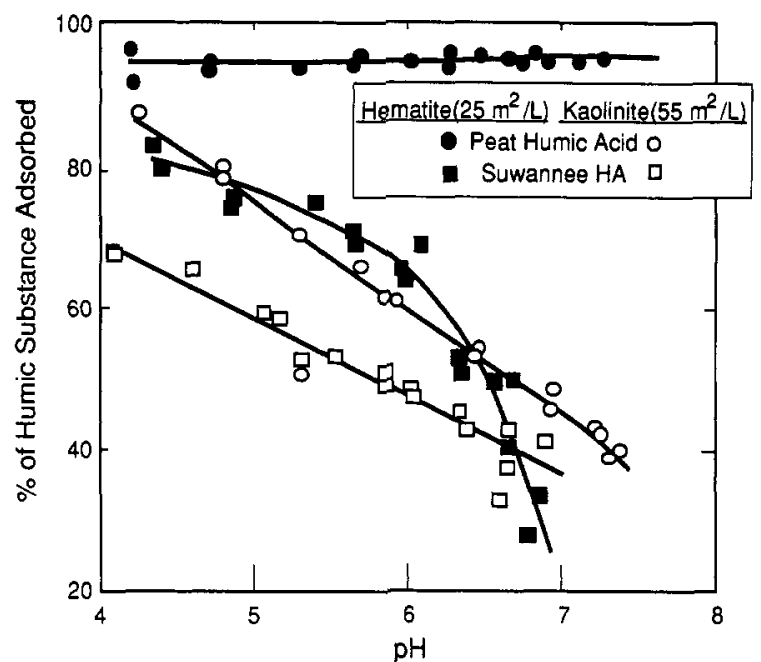

Figure 1. Fractional adsorption of peat humic acid and Suwannee humic acid at varying $\mathrm{pH}$. The initial humic acid concentration was 10 $\mathrm{mg}$ of $\mathrm{C} / \mathrm{L}$.

with different sorptivity for HOC. Approximately $170 \mathrm{mg}$ of $\mathrm{C} / \mathrm{L}$ humic acid and $1.8 \mathrm{~g}$ of hematite (solid to DOC ratio of $\sim 10: 1$ ) in $0.1 \mathrm{M} \mathrm{NaClO}_{4}$ were equilibrated for 20 $\mathrm{h}$ in a slowly revolving centrifuge tube. The $\mathrm{pH}$ was maintained at 4.5. The suspension was centrifuged and the supernatant was decanted and saved. The DOC of the supernatant was determined and combined with a proportional amount of hematite (maintaining the solid to DOC ratio used in the first equilibration) in a second centrifuge tube and allowed to equilibrate. This procedure was repeated four times, reducing the DOC of the supernatant to below $15 \mathrm{mg}$ of $\mathrm{C} / \mathrm{L}$. The humic-coated hematite fractions were washed with DOC-free electrolyte and centrifuged, and the supernatant was analyzed for organic carbon and discarded. Labeled dibenzothiophene $(0.43$ $\mu \mathrm{g} / \mathrm{mL}$ ) was added to the coated hematite fractions and allowed to equilibrate for $20 \mathrm{~h}$. Finally, the suspensions were centrifuged and the supernatant was sampled for ${ }^{14} \mathrm{C}$ activity.

\section{Results and Discussion}

Sorption of Humic Substances to Mineral Surfaces. The sorption characteristics of four humic substances, peat humic and fulvic acids and Suwannee humic and fulvic acids, were investigated on kaolinite and hematite. Sorption of humic substances increased with decreasing $\mathrm{pH}$ in response to positive charge development on the sorbents (Figure 1). This pattern was consistent with a ligand-exchange mechanism, as previously suggested for humic substances by others $(21,23,25,26,38)$. Evidence for organic carboxylate ligand exchange is indirect, often following the lines of evidence established for inorganic oxyanion ligand exchange (31). Sorption of humic substances by ligand exchange is believed to occur in the following sequence $(31,39)$ :

$$
\begin{gathered}
\mathrm{SOH}+\mathrm{H}^{+}-\mathrm{SOH}_{2}^{+} \\
\mathrm{SOH}_{2}^{+}+\mathrm{Hu}-\mathrm{C}(\mathrm{O}) \mathrm{O}^{-}-\mathrm{SOH}_{2}{ }^{+} \mathrm{O}^{-} \mathrm{C}(\mathrm{O})-\mathrm{Hu} \\
\mathrm{SOH}_{2}{ }^{+} \mathrm{O}^{-} \mathrm{C}(\mathrm{O})-\mathrm{Hu}-\mathrm{SOC}(\mathrm{O})-\mathrm{Hu}+\mathrm{H}_{2} \mathrm{O}
\end{gathered}
$$

where $\mathrm{SOH}$ represents the surface hydroxyl group on the sorbent, and $\mathrm{Hu}-\mathrm{COO}^{-}$represents the humic carboxyl group. The first step of this process is protonation (eq 1), which is believed to render the surface hydroxyl group more exchangeable (31). The protonation step is responsible, in part, for the $\mathrm{pH}$ dependence of the fractional 


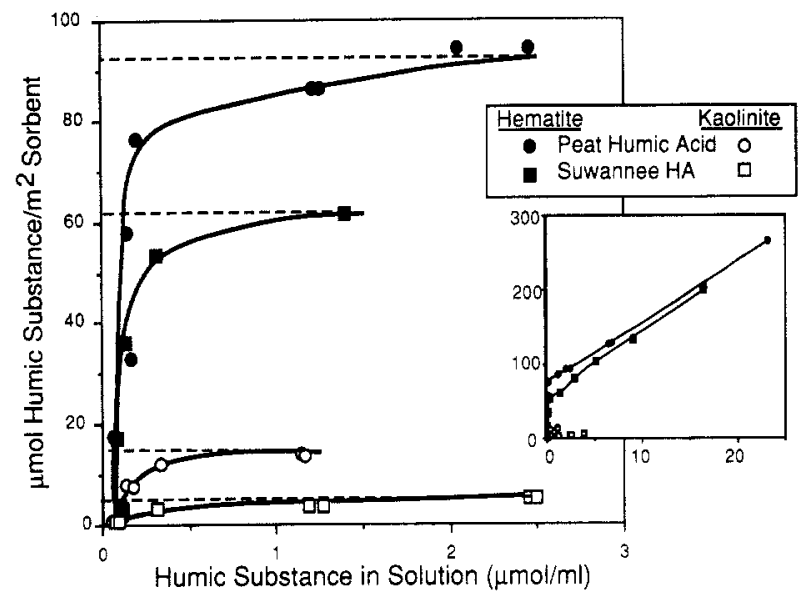

Flgure 2. Sorption isotherms of peat and Suwannee humic acids on hematite and kaolinite. Dashed lines define approximate sorption maxima (monolayer coverage). Expanded isotherms for humic acid sorption on hematite are shown in the inset.

sorption. The humic carboxyl groups may then form an outer-sphere surface complex with the protonated hydroxyl group (eq 2). Ligand exchange $\left(\mathrm{OH}_{2}\right.$ for $\left.\mathrm{Hu}-\mathrm{COO}^{-}\right)$is postulated to occur in the final step (eq 3 ), yielding an inner-sphere complex. In these experiments, the desorption of the humic substances from the sorbents was insignificant after 7 days, evidence for the formation of stable inner-sphere complexes between multiple carboxyl groups on the humic substance polyelectrolyte and surface hy. droxyl sites on the sorbents. We also note that increased protonation of carboxylate sites on the humic substances at lower $\mathrm{pH}$ may have enhanced sorption by (1) increasing the possibility for hydrogen bond formation with the mineral surfaces and (2) decreasing electrostatic repulsion between the humic substance and fixed negative charge sites on kaolinite.

The sorption of the individual humic substances on kaolinite and hematite differed primarily because (1) the sorbents were present at different concentrations $\left(\mathrm{m}^{2} / \mathrm{L}\right)$ and (2) their surfaces contain hydroxylated sites with different site densities (sites $/ \mathrm{nm}^{2}$ ) and structural/crystallographic locations. The concentration of hematite hydroxyl sites in the sorbent suspensions shown in Figure 1 was $\sim 4$ times greater than the corresponding concentration of sites on kaolinite, and hydroxyl sites on hematite are distributed more evenly across the mineral surface than on kaolinite (31). The aluminol groups on kaolinite are restricted to the edges of the layer silicate platelet, where steric interactions may limit both the amount and the rate of humic acid sorption (1). Equilibrium sorption occurred within the first hour on hematite, while equilibrium sorption on kaolinite occurred within 8-12 h. This difference may be the result of steric interactions during the ligand-exchange reaction. Steric interactions may also influence the number of attachment points available and the orientation of the humic substance on the mineral surface.

Isotherms for the sorption of humic substances on hematite and kaolinite (Figure 2) followed a Langmuir-type (L) curve and are similar to previously reported isotherms for humic substance sorption on mineral surfaces $(23,38)$. Such isotherms showed high affinity sorption at low surface coverage that rapidly reached sorption maxima ranging from 5 to $92 \mu \mathrm{mol} \mathrm{C} / \mathrm{m}^{2}$ of sorbent. At high concentrations of humic acid, the sorption of peat and Suwannee humic acids on hematite displayed non-Langmurian behavior (inset of Figure 2), presumably due to hydrophobic humic-humic interactions resulting in mul-

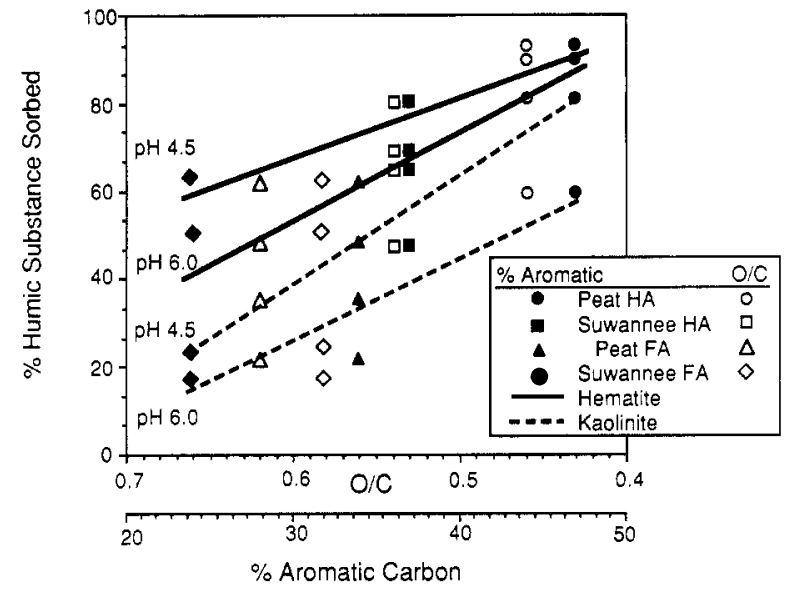

Figure 3. Sorption of four humic substances as a function of aromatic carbon content and $\mathrm{O} / \mathrm{C}$ ratios on hematite and kaolinite.

tiple layering of humic acids on the mineral surface. The initial slope of the isotherms was steeper for hematite than for kaolinite reflecting both the different site concentrations and the relative affinity of the humic substances for the iron and aluminol hydroxyl groups. If we assume that the tendency of an organic ligand, such as humic acid, to form surface complexes with metal-hydroxyl groups may be similar to that of humic acids forming complexes with the free metal (21), then the results presented here are consistent with Theng and Scharpenseel (40). Through cation bridging, Theng and Scharpenseel showed that the sorption of humic acid was greater by $\mathrm{Fe}$-saturated montmorillonite than by Al-saturated montmorillonite. The Langmuir method has previously been applied to determine the maximum sorption density by assuming that the plateau or sorption maximum of the Langmuir curve represents monolayer coverage of the solid by the polymer $(21,41,42)$. Monolayer coverage does not necessarily represent saturation of surface hydroxyl sites by direct coordination with carboxyl groups on the polyelectrolyte.

At the same $\mathrm{pH}$, the amount of humic substance sorbed on a specific mineral substrate was proportional to the aromatic carbon content and inversely proportional to the $\mathrm{O} / \mathrm{C}$ ratio (Figure 3). Humic acids were invariably adsorbed more strongly than fulvic acids. Although the characteristics of humic substances may vary widely depending on the source material, it is generally accepted that humic acids have greater phenolic content, greater aromaticity, greater carbon, greater molar volume (molecular weight), and less oxygen than the corresponding fulvic acids (43-45). Elemental ratios of oxygen and carbon have previously been used as an indication of the polarity of the humic substance $(10,13)$. A high $\mathrm{O} / \mathrm{C}$ ratio would indicate high polarity and consequently greater water solubility, consistent with the inverse relationship between $\mathrm{O} / \mathrm{C}$ and sorption of the humic substances on the mineral surfaces.

Not only do humic acids have greater molar volumes than fulvic acids, but the molar volumes of humic substances from terrestrial sources are generally higher than those of humic substances from aquatic sources $(43,44$, 46-48). Therefore, the order of sorption, peat humic acid $>$ Suwannee humic acid $>$ peat fulvic acid $>$ Suwannee fulvic acid, may also reflect decreasing molecular weight. Previous investigations have shown that the sorption of natual organic matter by soil minerals increases with the molecular weight of the organic matter (22). Also, polyelectrolyte sorption to mineral surfaces increases as the number of potential points of attachment on the polyelectrolyte increases $(49,50)$. By analogy, it can be con- 


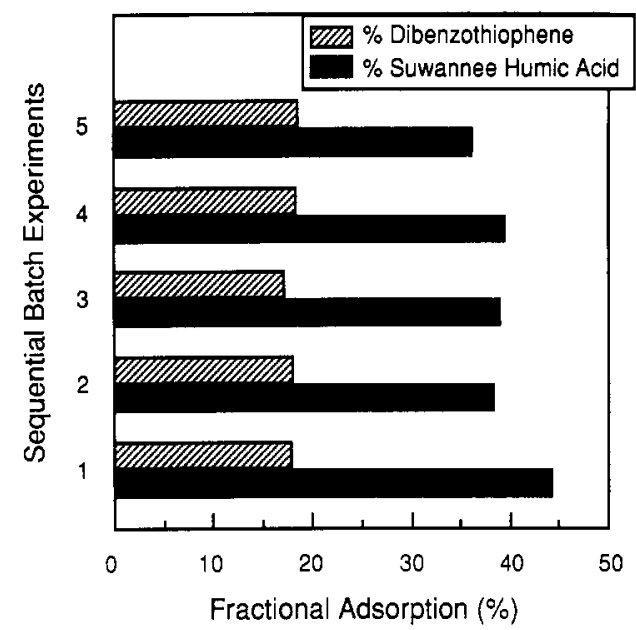

Figure 4. Fractional adsorption of Suwannee humic acid on hematite and subsequent adsorption of dibenzothiophene on these humic acid coatings. Unadsorbed DOC from the first batch experiment was reacted with clean hematite in the second batch experiment, and so on, untll the amount of unadsorbed DOC (fifth batch experiment) was below $15 \mathrm{mg}$ of $\mathrm{C} / \mathrm{L}$.

cluded that humic substances with higher molecular weight should be more strongly sorbed because their carboxyl group content is greater on a molar basis.

The relationship between enhanced humic substance sorption and such properties as high aromaticity, low polarity, and high molecular weight suggests that humic acids are more likely to bind to hydroxylated sites on mineral surfaces than fulvic acids. Field observation suggests that humic substances fractionate onto aquifer solids while being transported from the recharge zone to the distal portion of the aquifer $(51,52)$. Enhanced sorption of the more hydrophobic fraction of the DOC (i.e., the humic acids) by mineral sorbents will result in the groundwater DOC being relatively enriched in fulvic acids. It is not surprising, therefore, that fulvic acids are typically the dominant humic substance in groundwater $(44,53)$.

Although isolated humic acid fractions (peat humic acid and Suwannee humic acid) were used in our experiments, humic acids are by definition heterogeneous macromolecules lacking a definite structure. Wershaw (54) has shown that soil humic acids can be separated by adsorption chromatography on Sephadex into a series of fractions with different chemical and physical properties. If fractionation of humic substances also occurred on the mineral surfaces in this study, then interpretation of the sorption behavior using the "average" characterization data (Table II) would not be valid. Therefore, a humic acid fractionation experiment was performed to determine whether the characteristics of the humic coating would change upon sequential sorption to clean mineral surfaces. In these batch experiments, Suwannee humic acid in the nonsorbed supernatant was used in the subsequent reaction with clean hematite. The hypothesis was that if fractionation occurred, then both the fractional sorption of the humic substance on the mineral surface and the cosorption of HOC would not remain constant in sequential batch experiments where the carbon/sorbent ratio was maintained. The experiment was analogous to the removal of humic acid by sorption to aquifer solids as it travels along a given flow path. As shown in Figure 4, neither the fractional sorption of humic acid nor the fractional sorption of dibenzothiophene changed significantly between successive batch experiments. It may be concluded that those characteristics of Suwannee humic acid that affect sorption to the mineral phase and sorption of the HOC are uniform and that significant fractionation of the Suwannee humic

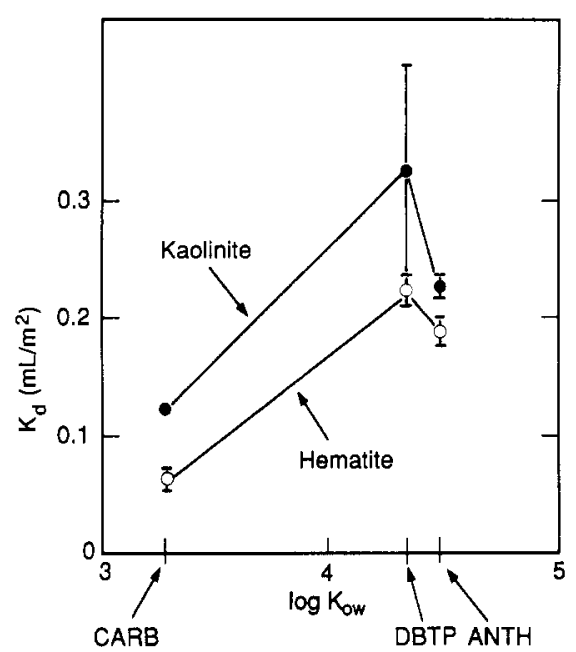

Figure 5. Experimental distribution coefficients for the sorption of carbazole (CARB), dibenzothiophene (DBTP), and anthracene (ANTH) on organic-free hematite and kaolinite.

acid through mixed sorption reactions did not occur. We assume, but did not prove, that peat humic acid would behave on these sorbents in a comparable manner.

Sorption of HOC to Humic-Coated Minerals. The sorption of carbazole, dibenzothiophene, and anthracene was investigated on hematite, kaolinite, and CP-clay that had been coated with either peat humic acid or Suwannee humic acid. In these experiments, $f_{\mathrm{oc}}$ values were varied over the range of $0.001-0.01$ to encompass the organic carbon concentrations found in low-carbon groundwaters and aquifers (see organic carbon concentrations in refs 55-59). Low-carbon mineral systems were emphasized because past investigations have shown that $K_{o c}-K_{o w}$ relationships tend to deteriorate below an $f_{\mathrm{oc}}$ of $0.001(1,16$, 60 ). The natural clay fraction (CP-clay) was used to show that the results of experiments with the surrogate sorbents (hematite and kaolinite) were, in fact, relevant to natural subsurface materials containing these mineral phases.

Sorption of the HOC was very low on the bare mineral surfaces because they had been pretreated to remove any small amounts of organic carbon that might be present. Sorption was, nonetheless, measurable because the mineral surface areas used in the sorption experiments were large $\left(1600 \mathrm{~m}^{2} / \mathrm{L}\right.$ for kaolinite and $400 \mathrm{~m}^{2} / \mathrm{L}$ for hematite). At an initial sorbate concentration of $25 \%$ water solubility, the percent sorption of carbazole, dibenzothiophene, and anthracene was 3,6 , and $8 \%$, respectively, for hematite, and 6,19 , and $25 \%$, respectively, for kaolinite (data not shown). Single-concentration $K_{d}$ values were calculated from these data and were normalized to surface area $\left(\mathrm{mL} / \mathrm{m}^{2}\right)$. These $K_{\mathrm{d}}$ values were generally low in magnitude, but highest for kaolinite (Figure 5). The magnitude of these $K_{\mathrm{d}}$ values, when differences in surface areas are taken into account, was comparable to those reported by Stauffer and MacIntyre (61) for the sorption of different $\mathrm{HOC}$ on iron and aluminum oxides. The $K_{\mathrm{d}}$ values did not increase uniformly with $K_{\text {ow }}$, as has been reported by Schwarzenbach and Westall (16) and Curtis et al. (18), but rather were greatest for dibenzothiophene. The higher sorptivity of kaolinite over hematite may tentatively be ascribed to the presence of the siloxane and gibbsite basal planes, which contain few ionizable hydroxyl sites and exhibit more hydrophobic characteristics (62).

As shown in Figure 6, increasing quantities of sorbed humic substances increased the fractional sorption of anthracene, dibenzothiophene, and carbazole. Anthracene $\left(\log K_{\text {ow }}=4.45\right)$, the most hydrophobic HOC, showed the greatest sorption enhancement, followed by dibenzo- 


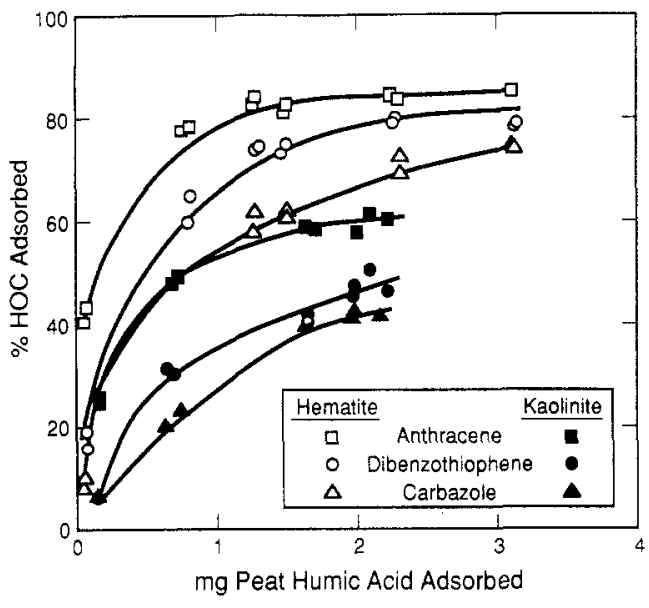

Flgure 6. Comparison of the fractional adsorption of $\mathrm{HOC}$ on hematite and kaolinite coated with peat humic acid.

thiophene ( $\log K_{\text {ow }}=4.38$ ), and carbazole $\left(\log K_{\text {ow }}=3.29\right.$ ). Peat humic acid coatings associated with hematite showed greater sorption enhancement of the HOC than the same amount of peat humic acid sorbed to kaolinite. However, the sorption enhancement was not linear. The HOC sorption was increased most dramatically per unit of sorbed humic carbon at the lowest $f_{o c}$. This apparent nonlinear response to increasing surface carbon contrasted with the results of Chiou et al. (13), who reported a linear increase in the apparent solubility of HOC with increasing concentration of dissolved humic substances. As concentrations of humic substances bound to the mineral surface increase, they may adopt configurations that limit carbon availability for HOC sorption (1) or that limit the size and accessibility of hydrophobic domains on the humic coating.

The contribution of the mineral sorbent to HOC sorption was removed for calculating (1) the amount of HOC associated with the sorbed humic phase and (2) the carbon-normalized binding constant for the sorbed humic phase. A rigorous calculation of the mineral surface contribution to sorption requires that the surface area of the mineral sorbent exposed to the HOC be known (18); that is

$$
S_{\min }=K_{\mathrm{d}(\mathrm{s})} C \hat{s}
$$

where $S_{\min }$ is the adsorbed HOC concentration $(\mathrm{mol} / \mathrm{g}$ ) attributed to the mineral surface, $K_{\mathrm{d}(\mathrm{s})}$ is the mineral surface-binding constant $\left(\mathrm{mL} / \mathrm{m}^{2}\right)$ as calculated from a sorption experiment with clean mineral surface (i.e., Figure $5), C$ is the HOC concentration in solution $(\mathrm{mol} / \mathrm{mL})$, and $\hat{s}$ is the exposed surface area of the mineral $\left(\mathrm{m}^{2} / \mathrm{g}\right)$. A value for the organic-only contribution to $S, S_{\text {org }}$, can then be calculated:

$$
S_{\text {org }}=S-S_{\min }
$$

The exposed surface area of the mineral, $\hat{s}$, was calculated by assuming that the plateau in the adsorption density in the humic-mineral isotherms (Figure 2) corresponded to monolayer coverage. With this assumption, the surface area occupied by a mole of humic acid carbon was calculated, and this parameter was used to determine the fractional coverage of the mineral surface by humic material in each HOC cosorption experiment. The fractional coverage of hematite varied from 1 to $96 \%$ over the $f_{\text {oc }}$ range $0.01-0.5 \%$. The estimates of humic surface coverage in the kaolinite experiments ranged from $7 \%$ to approximately two monolayers on the edge sites where aluminol groups are exposed. We surmise that most of the kaolinite mineral surface comprising the basal plane would

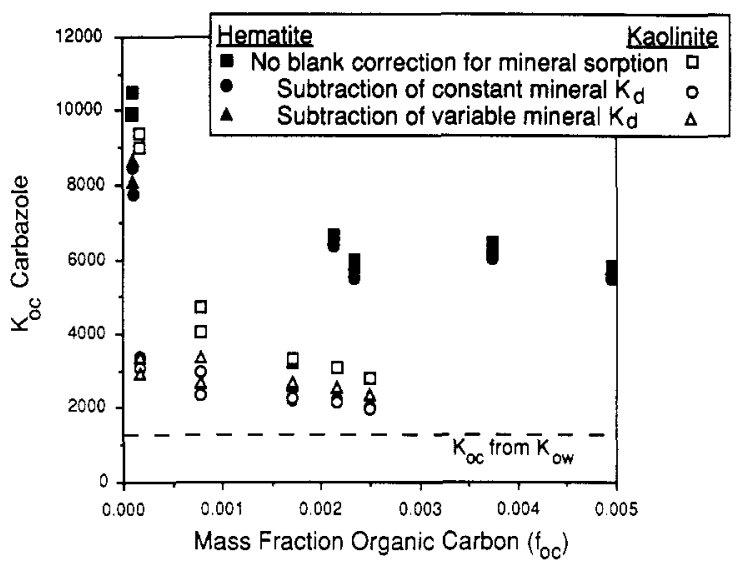

Figure 7. Effect of mineral adsorption of carbazole on the calculated $K_{\propto}$ values. The constant mineral $K_{d}$ represents the amount of carbazole adsorption to bare mineral surface. Variable mineral $K_{\mathrm{d}}$ values are adjusted to the amount of exposed mineral surface on humiccoated sorbents.

be uncovered by the humic substance. Lockhart (24) concluded that the basal plane of kaolinite was free of organic substances in a humate-clay association with $6 \%$ organic carbon.

Carbon-normalized sorption constants $\left(K_{o c}\right)$ were calculated from the sorption data in Figure 6 according to the relation

$$
K_{\mathrm{oc}}=\left(S-S_{\min }\right) /\left(C f_{\mathrm{oc}}\right)
$$

where $S$ is total adsorbed HOC (in $\mathrm{mol} / \mathrm{g}$ ), $S_{\min }$ is $\mathrm{HOC}$ adsorbed to the mineral surface in the absence of the humic substance, $C$ is the equilibrium concentration (in $\mathrm{mol} / \mathrm{mL}$ ), and $f_{\mathrm{oc}}$ is the mass fraction organic carbon. As shown in Figure 7, the correction for mineral sorption has the greatest effect on the $K_{o c}$ at the lowest coverage of humic coating (or conversely, the largest amount of exposed mineral surface). The corrections for mineral sorption on kaolinite are larger than hematite because of the greater amount of HOC sorption to the bare kaolinite surface. The subtraction of mineral $K_{\mathrm{d}}$ values that vary with the amount of exposed mineral surface produced $K_{o c}$ values that were very similar to those calculated when a constant blank mineral $K_{\mathrm{d}}$ was subtracted from the experimental data; therefore, the $K_{o c}$ values were relatively insensitive to the estimated exposed surface area of the mineral sorbent. The mass fraction organic carbon of humic-coated sorbents was calculated according to the equation

$$
f_{o c}=(\mathrm{mg} \text { of adsorbed } \mathrm{C} / \mathrm{g} \text { of sorbent }) \times 1000
$$

The calculated $K_{\infty}$ values for carbazole, dibenzothiophene, and anthracene were relatively constant with surface coverage of humic substance, except at the lower $f_{o c}$ values (Figure 8). The most variation of $K_{o c}$ with $f_{o c}$ occurred with dibenzothiophene and anthracene sorbed to hematite coated with peat humic acid. Mineral surface and the type of humic coating resulted in variations in the calculated $K_{\mathrm{oc}}$ values for a given $\mathrm{HOC}$. The most aromatic coating, peat humic acid, consistently showed the greatest $K_{\text {oc }}$, especially when sorbed to hematite. This observation was consistent with Gauthier et al. (12), who found that the affinity of dissolvd humic acid for pyrene increased with increasing aromaticity.

The $K_{\mathrm{oc}}$ values in Figure 8 were also compared with the $K_{\text {oc }}$ calculated from the $K_{\text {ow }}$ (Table III). For carbazole, the experimental $K_{\mathrm{oc}}$ values ranged from around 1000 to 8000. These results agreed with those of Ainsworth et al. (7), who observed $K_{\text {oc }}$ values for carbazole ranging from 


\begin{tabular}{|c|c|c|c|c|c|c|c|}
\hline & MW & $\begin{array}{l}\text { solubility, } \\
\mathrm{mg} / \mathrm{L}\end{array}$ & $\mathrm{mp},{ }^{\circ} \mathrm{C}$ & $\log K_{\text {ow }}$ & $K_{\mathrm{oc}}{ }^{a}\left(K_{\mathrm{ow}}\right)$ & $K_{o c}^{b}$ (solubility) & $K_{\infty}(\operatorname{exptl})$ \\
\hline carbazole & 167.2 & 1.88 & 245 & 3.29 & 1200 & 460 & $470-8000^{c}$ \\
\hline dibenzothiophene & 184.3 & 1.47 & 99 & 4.38 & 14800 & 15200 & $1500-36000^{d}$ \\
\hline anthracene & 178.2 & 0.075 & 216 & 4.45 & 17400 & 17900 & $10000-500000^{e}$ \\
\hline
\end{tabular}

${ }^{a} \log K_{\mathrm{oc}}=\log K_{\mathrm{ow}}-0.21(1) .{ }^{b} \log K_{\mathrm{oc}}=-0.921 \log x_{\mathrm{s}}-0.00953\left(\mathrm{mp} 25^{\circ} \mathrm{C}\right)-1.405(1)$. ${ }^{\mathrm{c}}$ Reference $7 .{ }^{d}$ References 7 and $62 .{ }^{\mathrm{e}}$ References 2,64 , and 65 .
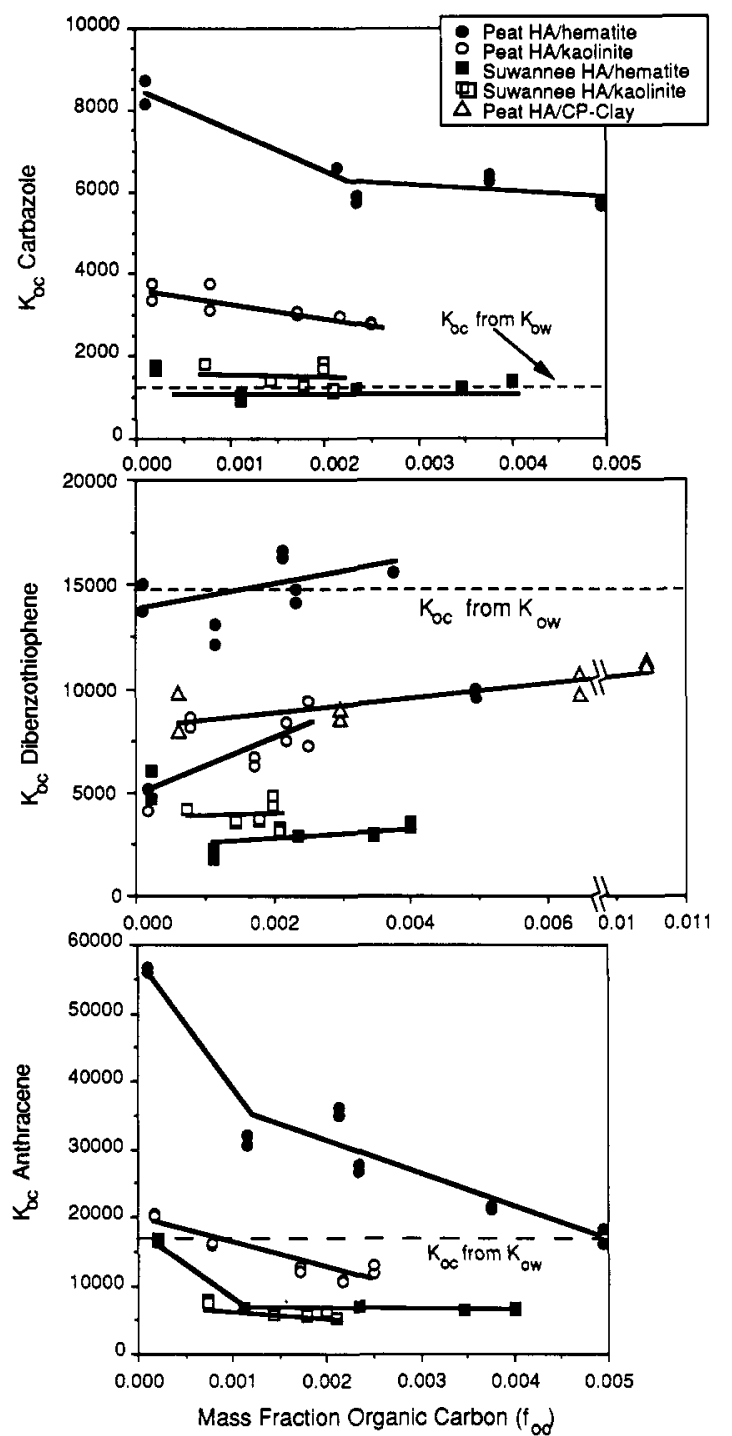

Floure 8. Calculated $K_{\infty}$ values for carbazole, dibenzothiophene, and anthracene on hematite and kaolinite coated with peat humic acid or Suwannee humic acid. The $K_{o c}$ values for dibenzothiophene sorbed to CP-clay are also shown.

470 to 8000 with different soil and subsoil materials. Ainsworth et al. (7) attributed these variations in the $K_{o}$ to differences in the structure and chemical properties of the organic sorbent. Chiou et al. $(10,13)$ used the oxygen-to-carbon ratio from elemental analyses as an approximate index of the polarity of the humic substances. Less polar humic substances exhibit low $\mathrm{O} / \mathrm{C}$ ratios and show greater sorption enhancement of HOC. On the basis of the elemental analyses, peat humic acid had the lowest polarity (Table II) and showed the greatest sorption enhancement of HOC, especially when associated with hematite. Similar results were presented by Garbarini and Lion (6), who found that the carbon-to-oxygen ratio of the organic matter accounted for over $75 \%$ of the variation in $K_{d}$ for toluene and TCE.

The $K_{o c}$ values for dibenzothiophene ranged from those predicted from the $K_{\text {ow }}$ to values an order of magnitude lower (Figure 8). Again, sorption was most enhanced on hematite coated with peat humic acid. The observed $K_{\mathrm{oc}}$ values for dibenzothiophene were remarkably constant down to the lowest $f_{\mathrm{oc}}$. The CP-clay coated with peat humic acid yielded $K_{o c}$ values that were intermediate between those for hematite coated with peat humic acid and those for kaolinite coated with peat humic acid, suggesting that the relatively minor mineralogic component, hematite, in this clay fraction dominates the sorption of dibenzothiophene through the association with the humic acid. Reported $K_{o c}$ values for dibenzothiophene range from 1500 to $36000(62,63)$. On high-carbon soils and sediments, Hassett et al. (62) measured $K_{\mathrm{oc}}$ values ranging from 5000 to $\sim 19000$, which are somewhat higher than the range observed here (1000-15000).

The $K_{\mathrm{oc}}$ values for anthracene were both above and below $K_{o c}$ values estimated from the $K_{\text {ow }}$ (Figure 8). Reported $K_{o c}$ values for anthracene binding to dissolved humic materials have ranged from 10000 to 60000 when determined by fluorescence quenching (64), from 10000 to 80000 when determined by reverse-phase chromatography (65), and from 30000 to 500000 when determined by dialysis (65). The values reported in this work generally range from 5000 to 35000 ; with one anomalously high value at $\sim 56000$.

The experimental $K_{\mathrm{oc}}$ values presented here for anthracene on humic-coated mineral sorbent are lower than the values determined with humic substances in the dissolved phase, suggesting that humics sorbed to mineral surfaces adopt interfacial configurations that reduce HOC sorption. Unfortunately, data for aqueous-phase association of carbazole and dibenzothiophene with humic substances, comparable to anthracene, are not available to substantiate this statement.

Most significant were the observations that a given humic substance exhibited a different sorptivity for HOC on different mineral surfaces and that these differences held over a wide range in surface coverages $\left(f_{o c}\right)$ by the humic substance. The mineral surface apparently affects the interfacial configuration of the humic substance, possibly altering the size of hydrophobic domains on the humic molecule or their accessibility to HOC. Humic materials sorbed to hematite were more selective than 
Table IV. Freundlich Constants for HOC Sorption on Kaolinite and Hematite Coated with High and Low Concentrations of Peat Humic Acid ${ }^{a}$

\begin{tabular}{|c|c|c|c|c|c|c|c|}
\hline & & by dif & & desorp & irect $m$ & ment & \\
\hline & $\log K_{\mathrm{F}}$ & $N$ & $r^{2}$ & $\log K_{F}$ & $N$ & $r^{2}$ & $95 \%$ CI of slope \\
\hline $\begin{array}{l}\text { kaolinite } \\
\text { carbazole }\end{array}$ & & & & & & & \\
\hline high $f_{o c}=0.0025$ & 0.618 & 0.777 & 1.000 & 0.581 & 0.781 & 0.999 & $0.770-0.785$ \\
\hline $\begin{array}{c}\text { low } f_{o c}=0.0002 \\
\text { dibenzothiophene }\end{array}$ & 0.121 & 0.852 & 0.998 & -0.051 & 0.824 & 0.991 & $0.830-0.875$ \\
\hline high $f_{o c}=0.0025$ & 1.055 & 0.848 & 0.998 & 1.005 & 0.840 & 0.996 & $0.822-0.874$ \\
\hline $\begin{array}{l}\text { low } \mathrm{f}_{\alpha}=0.0002 \\
\text { anthracene }\end{array}$ & 0.481 & 0.909 & 0.999 & 0.336 & 0.867 & 0.996 & $0.875-0.942$ \\
\hline high $\mathrm{f}_{\mathrm{oc}}=0.0025$ & 1.438 & 0.913 & 0.997 & 1.389 & 0.918 & 0.998 & $0.887-0.940$ \\
\hline $\operatorname{low}_{o c}=0.0002$ & 0.360 & 0.815 & 0.998 & 0.407 & 0.842 & 0.998 & $0.790-0.841$ \\
\hline $\begin{array}{l}\text { hematite } \\
\text { carbazole }\end{array}$ & & & & & & & \\
\hline high $\mathrm{f}_{o c}=0.0028$ & 0.597 & 0.695 & 0.995 & 0.730 & 0.747 & 0.992 & $0.661-0.729$ \\
\hline high $\mathrm{f}_{o c}=0.0047^{c}$ & 0.734 & 0.708 & 0.997 & & & & $0.670-0.747$ \\
\hline low $f_{o c}=0.0002$ & -0.415 & 0.676 & 0.924 & -0.438 & 0.748 & 0.910 & $0.539-0.813$ \\
\hline $\begin{array}{l}\text { low } f_{o c}=0.0002^{c} \\
\text { dibenzothiophene }\end{array}$ & -0.377 & 0.691 & 0.998 & & & & $0.615-0.766$ \\
\hline high $\mathrm{f}_{o c}=0.0028$ & 1.692 & 0.965 & 0.983 & 1.694 & 0.970 & 0.977 & $0.868-1.061$ \\
\hline high $\mathrm{f}_{o c}=0.0047^{c}$ & 1.257 & 0.790 & 0.995 & & & & $0.737-0.843$ \\
\hline low $\mathrm{f}_{\mathrm{oc}}=0.0002$ & -0.135 & 0.717 & 0.703 & -0.116 & 0.731 & 0.692 & $0.388-1.045$ \\
\hline low $\mathrm{f}_{\alpha c}=0.0002^{c}$ & -0.405 & 0.647 & 0.955 & & & & $0.507-0.787$ \\
\hline $\begin{array}{l}\text { CP-clayd } \\
\text { anthracene }\end{array}$ & -1.708 & 1.055 & 0.965 & & & & $0.828-1.255$ \\
\hline high $\mathrm{f}_{o c}=0.0028$ & 2.007 & 0.945 & 0.970 & 2.106 & 0.983 & 0.964 & $0.828-1.063$ \\
\hline low $f_{o c}=0.0002$ & 0.535 & 0.843 & 0.954 & 0.311 & 0.835 & 0.905 & $0.711-0.973$ \\
\hline
\end{tabular}

a The experimental Freundlich constants were determined by difference (measurement of the counts in solution) and by desorption of the HOC from the sorbent and direct measurement. ${ }^{b}$ Confidence intervals (CI) shown are based on the "sorption by difference" Freundlich constants. ${ }^{e}$ Replicate isotherms with a different batch of hematite where sorption was only calculated by difference. ${ }^{d}$ Dibenzothiophene sorption on natural, untreated, CP.Clay $f_{o c}=0.0004$.

identical materials sorbed to kaolinite. The more uniform distribution of hydroxyl sites over the entire hematite surface may allow the humic substances to adopt a more open structure on the surface, yielding a larger hydrophobic area than would occur under comparable $f_{o c}$ on kaolinite. In contrast, the humic substances on kaolinite are believed to be restricted to a smaller percentage of the total sorbent surface area at the edge. The conformation of the edge-adsorbed humic substances is apparently less conducive to HOC sorption.

Sorption isotherms for $\mathrm{HOC}$ on hematite and kaolinite with bound humic substances were linear on a log-log basis (Figure 9a and b) and conformed to the Freundlich equation:

$$
\log S=\log K_{\mathrm{F}}+N \log C_{\mathrm{e}}
$$

where $K_{\mathrm{F}}$ and $N$ are constants specific to the coated sorbent, $S$ is micromoles of HOC adsorbed per gram of solid, and $C_{\mathrm{e}}$ is micromoles of HOC per milliliter of solution. The Freundlich constants and correlation coefficients are shown in Table IV. The best fit linear regressions to the data in Figure 9 generally did not exhibit a slope of 1 (i.e. Freundlich $N \neq 1$ ), although the $95 \%$ confidence interval for the isotherm data with greatest scatter sometimes encompassed 1 (Table IV). Slopes of nonunity were observed regardless of whether sorption was measured by aqueous-phase difference or by direct analysis of the sorbent phase (Table IV); in fact, the statistics of these two types of sorption measurements were comparable. Both humic-coated kaolinite and hematite exhibited $N$ values of less than unity. The slope of the high $f_{\text {oc }}$ isotherms on both kaolinite and hematite increased with sorbate $K_{\text {ow }}$ or hydrophobicity. Therefore, isotherm slopes for anthracene, the most hydrophobic compound, were close to unity. For a given $\mathrm{HOC}$, the intercept $K_{\mathrm{F}}$, was generally greater when peat humic acid was associated with hematite than with

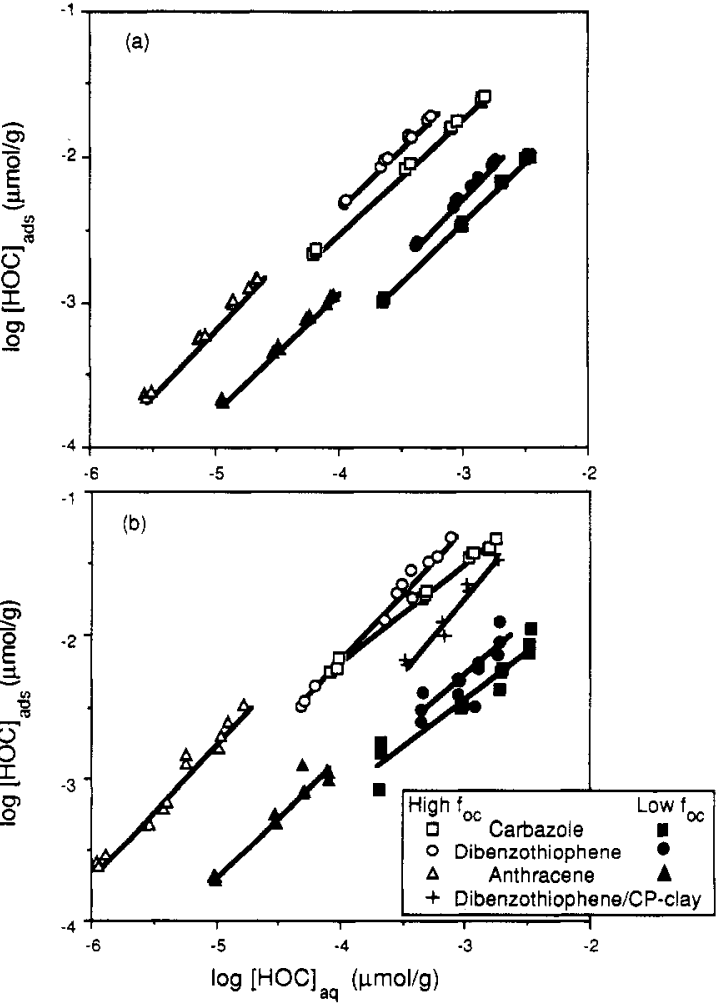

Figure 9. Sorption isotherms of HOC on kaolinite (a) and hematite (b) coated with high and low concentrations of peat humic acid. Freundlich constants are shown in Table IV.

kaolinite, consistent with the $K_{\text {oc }}$ values in Figure 8 .

Chiou et al. $(5,66)$ argued that linearity of the HOC isotherm (i.e., $N=1$ ) is evidence for partitioning of HOC into an organic phase. The nonlinearity of the isotherms (i.e., $N \neq 1$ ) on the mineral-humate sorbents suggest that 


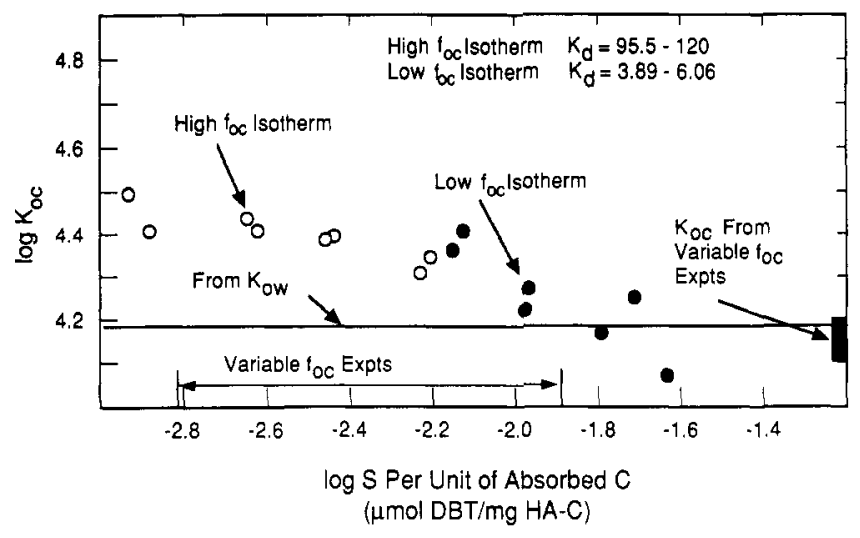

Figure 10. Comparison of calculated $K_{o c}$ values from isotherms of dibenzothiophene on hematite coated with peat humic acid with the $K_{o c}$ from variable $f_{\infty}$ experiments.

the sorbed humic substance is behaving as a hydrophobic surface rather than a hydrophobic phase. The CP-clay $(N$ $=1$ ) differs in its isotherm behavior from the coated hematite, suggesting HOC may be sorbed by partitioning in the natural clay.

Because the Freundlich $N$ value was not unity, a single $K_{\text {oc }}$ could not be calculated for the sorbed humic phase from the isotherm data in Figure 9 . Instead, $K_{\infty c}$ values were calculated for each isotherm point on selected isotherms in Figure 9 to assess the trend in $K_{\mathrm{oc}}$ with HOC sorption density. The calculated single-point $K_{o c}$ values for dibenzothiophene on hematite coated with high and low $f_{o c}$ were plotted together in Figure 10. These data show that the sorbed peat humic acid acts uniformly as a phase, regardless of its $f_{o c}$ on the sorbent. The decrease in $K_{o c}$ with increasing sorption density suggests that adsorption (as opposed to partitioning) is the dominant sorption process for HOC on these humic-mineral sorbents and that adsorption sites are hetereogeneous. The most energetic or strongly binding sites, possibly associated with the most hydrophobic domains accessible to the HOC, are occupied first, yielding higher $K_{o c}$ values at low adsorption density.

\section{Conclusions}

The formation of natural organic coatings on kaolinite and hematite was consistent with ligand exchange between carboxylic acid groups on the humic substance and hydroxylated surface sites on the solids. The sorption of humic substances to both hematite and kaolinite was proportional to their aromatic carbon content and inversely proportional to their $\mathrm{O} / \mathrm{C}$ ratio. Humic acids were invariably more strongly adsorbed than fulvic acids. These observations suggest that, in a shallow aquifer, humic acids from either terrestrial or aquatic sources are more likely to form organic coatings on mineral surfaces than fulvic acids. Furthermore, these findings suggest that the organic carbon associated with mineral surfaces in aquifers will have high aromatic carbon, in contrast to the DOC in groundwater, which typically has a high percentage of aliphatic carbon.

In the absence of organic coatings or natural organic impurities, kaolinite and hematite sorb HOC very weakly, and large mineral surface areas $\left(400-1600 \mathrm{~m}^{2} / \mathrm{L}\right)$ that greatly exceed those found in groundwater were needed to measure a statistically significant change in solution concentration. Past studies of HOC sorption on mineral solids may have been influenced by organic impurities that were carefully removed in this study. Sorbed humic substances, however, greatly enhanced HOC sorption at low surface coverage and $f_{\text {oc }}$. The type of humic coating in- fluenced the amount of HOC adsorbed, and the most aromatic substance, peat humic acid, was the strongest sorbent. The lower polarity and higher molar volume of the peat humic acid as compared to the Suwannee humic acid apparently made peat humic acid more sorptive for HOC, when associated with the mineral surface.

The mineral surface, particularly the concentration and spatial distribution of hydroxyl sites, influenced the amount of $\mathrm{HOC}$ adsorbed on the organic coating. The difference in selectivity for the same humic substance on hematite and on kaolinite suggested that the mineral surface influences the structure of the sorbed humic substance in ways that are important to HOC sorption. The distribution of surface hydroxyl sites, which represents points of attachment for carboxyl groups on the humic substance, affects the interfacial configuration of the humic coatings, possibly altering the size or accessibility of the hydrophobic domain. Sorption isotherms of HOC on the humic-coated mineral substrates were nonlinear, implying that the sorption phenomenon was adsorption onto rather than partitioning into the surface organic phase.

Humic surface coatings may be an important sorbing phase for HOC in low-carbon substrates, which are typically found in aquifers. The $K_{\mathrm{oc}}$ values were strongly dependent on the chemical and physical properties of the organic coating. Furthermore, the experimental $K_{o c}$ values were both higher and lower than those predicted from the $K_{\text {ow }}$, suggesting that a wide range of error can be associated with contaminant transport models that estimate carbon sorption binding constants from $K_{\text {ow }}$. Most important, the accurate prediction of contaminant transport may require chemical information on both the dissolved and the mineral-bound organic matter.

Registry No. Carbazole, 86-74-8; dibenzothiophene, 132-65-0; anthracene, 120-12-7; hematite, 1317-60-8; kaolinite, 1318-74-7.

\section{Literature Cited}

(1) Karickoff, S. W. J. Hydraul. Eng. 1984, 110, 707-735.

(2) McCarthy, J. F.; Jimenez, B. D. Environ. Sci. Technol. 1985, 19, 1072-1076.

(3) Chin, Y.-P.; Weber, W. W. Environ. Sci. Technol. 1989, 23, 973-984.

(4) Lobartini, J. C.; Tan, D. H. Soil Sci. Soc. Am. J. 1988, 52, 125-130.

(5) Chiou, C. T.; Porter, P. E.; Schmedding, D. W. Environ. Sci. Technol. 1983, 17, 227-231.

(6) Garbarini, D. R.; Lion, L. W. Environ. Sci. Technol. 1986, $20,1263-1269$.

(7) Ainsworth, C. C.; Zachara, J. M.; Smith, S. C. Soil Sci. Soc. Am. J. 1989, 53, 1391-1404.

(8) Mingelgrin, U.; Gerstl, Z. J. Environ. Qual. 1983, 12, 1-11.

(9) Carter, C. W.; Suffet, I. H. Environ. Sci. Technol. 1982, 16, 735-740.

(10) Chiou, C. T.; Malcolm, R. L.; Brinton, T. I.; Kile, D. E. Environ. Sci. Technol. 1986, 20, 502-508.

(11) Hassett, J. P.; Anderson, M. A. Environ. Sci. Technol. 1979, $13,1526-1529$.

(12) Gauthier, T. D.; Seitz, W. R.; Grant, C. L. Environ. Sci. Technol. 1987, 21, 243-248.

(13) Chiou, C. T.; Kile, D. E.; Brinton, T. I.; Malcolm, R. L.; Leenheer, J. A.; MacCarthy, P. Environ. Sci. Technol. 1987, $21,1231-1234$.

(14) Khan, A.; Hassett, J. J.; Banwart, W. L.; Means, J. C.; Woods, S. G. Soil Sci. 1979, 128, 297-302.

(15) Banwart, W. L.; Hassett, J. J.; Wood, S. G.; Means, J. C. Soil Sci. 1982, 133, 42-47.

(16) Schwarzenbach, R. P.; Westall, J. Environ. Sci. Technol. 1981, 15, 1360-1367.

(17) Banerjee, P.; Piwoni, M. D.; Ebeid, K. Chemosphere 1985, 14, 1057-1067.

(18) Curtis, G. P.; Reinhard, M.; Roberts, P. V. In Geochemical Processes at Mineral Surfaces; Davis, J. A., Hayes, K. F., 
Eds; ACS Symposium Series 323; American Chemical Society: Washington, DC, 1986.

(19) McCarty, P. L.; Reinhard, M.; Rittmann, B. E. Environ. Sci. Technol. 1981, 15, 40-51.

(20) Turchenek, L. W.; Oades, J. M. Geoderma 1979, 21, 311-343.

(21) Kummert, R.; Stumm, W. J. Colloid Interface Sci. 1980 , $75,373-385$.

(22) Davis, J. A.; Gloor, R. Environ. Sci. Technol. 1981, 15, 1223-1229.

(23) Tipping, E. Geochim. Cosmochim. Acta 1981, 45, 191-199.

(24) Lockhart, N. C. Clays Clay Miner. 1981, 29, 413-422.

(25) Davis, J. A. Geochim. Cosmochim. Acta 1962, 46, 2381-2393.

(26) Tipping, E.; Cooke, D. Geochim. Cosmochim. Acta 1982, 46, 75-80.

(27) Tipping, E.; Heaton, M. J. Geochim. Cosmochim. Acta 1983, 47, 1393-1397.

(28) Morse, J. W. Mar. Chem. 1986, 20, 91-112.

(29) Johnston, C. T.; Sposito, G.; Birge, R. R. Clays Clay Miner. 1985, 33, 483-490.

(30) Zachara, J. M.; Cowan, C. E.; Schmidt, R. L.; Ainsworth, C. C. Clays Clay Miner. 1988, 36, 317-326.

(31) Sposito, G. The Surface Chemisty of Soils; Oxford University Press: New York, 1984.

(32) Yates, D. E. Ph.D. Thesis, The University of Melborne, Melborne, Australia, 1975.

(33) Liang, L.; Morgan, J. J. Aquat. Sci. 1990, 52, 32-55.

(34) Zachara, J. M.; Ainsworth, C. C.; Cowan, C. E.; Resch, C. T. Soil Sci. Soc. Am. J. 1989, 53, 418-428.

(35) Ferris, A. P.; Jepson, W. B. J. Colloid Interface Sci. 1975, $51,32-43$.

(36) Rand, B.; Melton, J. E. Nature 257, 214-216.

(37) Klute, A. Methods of Soil Analysis, Part 1. Physical and Mineralogical Methods, 2nd ed.; American Society of Agronomy, Soil Science Society of America, Inc.: Madison, WI, 1986.

(38) Parfitt, R. L.; Fraser, A. R.; Farmer, V. C. J. Soil Sci. 1977, $28,297-305$

(39) Zhang, P. C.; Sparks, D. L. Soil Sci. Soc. Am. J. 1989, 53, 1028-1034

(40) Theng, B. K. G.; Scharpenseel, H. W. The adsorption of ${ }^{14} \mathrm{C}$-labeled humic acid by montmorillonite. Proceedings of the International Clay Conference; Applied Publishing: Wilmette, IL, 1975; pp 643-653.

(41) Bohn, H.; McNeal, B.; O'Connor, G. Soil Chemistry; Wiley: New York, 1979.

(42) Liang, L. Dissertation, California Institute of Technology, 1988.

(43) Schnitzer, M.; Khan, S. U. Soil Organic Matter; Elsevier: New York, 1978.

(44) Thurman, E. M. Organic Geochemistry of Natural Waters; Martinus Nijhoff/Dr. W. Junk Publishers: Dordrecht, The Netherlands, 1985.

(45) Thorn, K. A.; Folan, D. W.; MacCarthy, P. Water-Resour. Invest. Rep. (U.S. Geol. Surv.) Submitted.

(46) Thurman, E. M.; Wershaw, R. L.; Malcolm, R. L.; Pinckney, D. J. Org. Geochem. 1982, 4, 27-35.
(47) Aiken, G.; McKnight, D. M.; Wershaw, R. L.; MacCarthy, P. Humic Substances in Soil, Sediment, and Water; Wiley: New York, 1985

(48) Reid, P. M.; Wilkinson, A. E.; Tipping, E.; Jones, M. N. Geochim. Cosmochim. Acta 1990, 54, 131-138.

(49) Hesselink, F. Th. In Adsorption from Solution at the Solid/Liquid Interface; Parfitt, G. D., Rochester, C. H. Eds.; Academic Press: London, 1983.

(50) Theng, B. K. G. Formation and Properties of Clay-Polymer Complexes; Developments in Soil Science 9; Elsevier Amsterdam, 1979.

(51) Thurman, E. M. Dissertation, University of Colorado, Boulder, 1979.

(52) Murphy, E. M.; Davis, S. N.; Long, A.; Donahue, D.; Jull A. J. T. Water Resour. Res. 1989, 25, 1893-1905.

(53) Thurman, E. M. In Humic Substances in Soil, Sediment, and Water; Aiken, G. R., McKnight, D. M., Wershaw, R. L., MacCarthy, P., Eds.; Wiley: New York, 1985.

(54) Wershaw, R. L. J. Contam. Hydrol. 1986, 1, 29-45.

(55) Schwarzenbach, R. P. Assessing the behavior and fate of hydrophobic organic compounds in the aquatic environment-General concepts and case studies emphasizing volatile halogenated hydrocarbons. Swiss Federal Institute of Technology, EAWAG, CH-8600 Dubendorf, 1983 (unpublished draft report).

(56) Schellenberg, K.; Leuenberger, C.; Schwarzenbach, R. P. Environ. Sci. Technol. 1984, 18, 652-657.

(57) Patterson, R. J.; Jackson, R. E.; Graham, B. W.; Chaput, D.; Priddle, M. Water Sci. Technol. 1985, 17, 57-69.

(58) Mackay, D. M.; Ball, W. P.; Durant, M. G. J. Contam. Hydrol. 1986, 1, 119-132.

(59) Uchrin, C. G.; Mangels, G. Environ. Toxicol. Chem. 1986, $5,339-343$.

(60) Mackay, D. M.; Roberts, P. V.; Cherry, J. A. Environ. Sci. Technol. 1985, 19, 384-392.

(61) Stauffer, T. B.; MacIntyre, W. G. Environ. Toxicol. Chem. 1986, 5, 949-955.

(62) Hassett, J. J.; Means, J. C.; Banwart, W. L.; Woods, S. G.; Ali, S.; Khan, A. J. Environ. Qual. 1980, 9, 184-186.

(63) Ainsworth, C. C.; Smith, S. C., submitted for publication in Soil Sci. Soc. Am. J.

(64) Gauthier, T. D.; Shane, E. C.; Guerin, W. F.; Seitz, W. R.; Grant, C. L. Environ. Sci. Technol. 1986, 20, 1162-1166.

(65) Landrum, P. F.; Nihart, S. R.; Eadie, B. J.; Gardner, W. S. Environ. Sci. Technol. 1984, 18, 187-192.

(66) Chiou, C. T.; Stroup, T. D. Environ. Sci. Technol. 1985 , $19,1196-1200$

Received for review January 12, 1990. Revised manuscript received May 23, 1990. Accepted May 30, 1990. This research was supported by the Subsurface Science Program of the Ecological Research Division (ERD) of the U.S. Department of Energy (DOE). The continued support of Dr.F. J. Wobber is appreciated. Pacific Northwest Laboratory is operated for DOE by Battelle Memorial Institute under Contract DE-AC06-76RLO 1830. 